\title{
First description of monogenean parasites in Lake Tanganyika: the cichlid Simochromis diagramma (Teleostei, Cichlidae) harbours a high diversity of Gyrodactylus species (Platyhelminthes, Monogenea) - CORRIGENDUM
}

\author{
MAARTEN P. M. VANHOVE, JOS SNOEKS, F. A. M. VOLCKAERT and TiNE HUYSE \\ doi: 10.1017/S0031182010001356 Published by Cambridge University Press, 15 October 2010 \\ Due to a technical calibration error, all metrics in this study have been overestimated by a factor two. \\ The consequences of this are as follows:
}

\section{RESULTS}

Species descriptions: all metrics mentioned in the diagnoses should be divided by two to acquire the correct values.

Figs. 1-2:

All scale bars $=10 \mu \mathrm{m}$.

Table 2: all metrics should be divided by two to acquire the correct values.

\section{DISCUSSION}

Comparisons with other Gyrodactylus spp.:

G. cichlidarum displays taller haptoral elements compared to G. sturmbaueri n. sp. Also, the dimensions of the haptoral elements of G. thlapi are not smaller than those of G. thysi n. sp.

G. zimbae n. sp. seems relatively large in comparison to the known African Gyrodactylus fauna, as it is larger (not twice as large) as most species described so far.

\section{REFERENCE}

Maarten P. M. Vanhove et al. (2010). First description of monogenean parasites in Lake Tanganyika: the cichid Sinochromis diagramma (Teleostei, Cichlidae) harbours a high diversity of Gyrodactylus species (Platyhelminthes, Monogenea). Parasitology Published by Cambridge University Press, 15 October 2010. doi: 10.1017/S0031182010001356 